\title{
RISK ASSESSMENT CRITERIA FOR MACHINE TOOLS SUBJECTED TO LARGE EARTHQUAKE HAZARDS: A PROPOSAL
}

\author{
PAULO DA SILVA \& IKUO TANABE \\ Department of Mechanical Engineering, Nagaoka University of Technology, Japan
}

\begin{abstract}
In recent years, several large earthquakes have struck Japan and brought severe destruction and human loss. As a lesson for the future, large amounts of data obtained from the earthquake aftermath reports were studied in order to attenuate the effect of future catastrophes. In this regard, the current study attempted to develop a set of risk assessment criteria through existing seismic data and mathematical models that mimic the movement of machine tools with screw jack mounting at the time of seismic activity. Particularly, data from the 2004 Chūetsu earthquake, the Great Hanshin earthquake and the 2011 Tōhoku earthquake was considered for this research. Moreover, the mathematical model proposals were presented and experimentally evaluated using a small mock-up structure of a machine tool. As a result, a simulation of the machine tool behavior during an earthquake was achieved by using real seismic data. It was concluded that; (1) the proposed model was able to define and estimate the possible motion behavior of machine tools under large vibrations to a certain degree; (2) the proposed method applied existing seismic data to predict the motion behavior of machine tools; (3) An approach for risk assessment of machine tools subjected to large earthquakes was presented.
\end{abstract}

Keywords: earthquake, risk management, vibration, machine tool, Japan.

\section{INTRODUCTION}

In recent years, three large earthquakes have struck Japan and made it into the international news for the severe destruction and human loss that came with them: the 1995 Great Hanshin earthquake [1], the 2004 Chūetsu earthquake [2], and the 2011 Tōhoku earthquake and tsunami [3]. Based on the earthquake aftermath reports [4], active plans for the recovery of the affected areas were set into motion and suggestions deemed as effective to improve such plans were also adopted [5]. In the same regard, adequate disaster prevention measures were incorporated and are being continuously improved. Particularly, the situation of the manufacturing sector in the wake of the earthquakes was considerably serious and resuming operations proved significantly difficult. Thus, not only the immediate losses due to the earthquake are an economic setback for Japan but also, and more significantly, the inability to recover rapidly underlined the importance of an earthquake-resilient manufacturing sector [6], [7]. Particularly, researches that focused on the aforementioned disasters have stressed that the accelerations generated by earthquakes do not generate considerable deformations due to internal stresses nor a considerable change in the machining accuracy of machine tools and its components. Instead, the problematic observed in machining workshop areas was the displacement or the overturn of the machine tools [8], [9]. Correspondingly, a set of risk assessment criteria to prevent machine tools from catastrophically moving, overturning or tumbling during an earthquake were proposed. Specifically, the impact of an earthquake was analysed by reproducing, through a lathe linear motor table, the acceleration data registered during a real earthquake over a small mock-up structure of a machine tool. The proposed analysis model was based on the dynamic forces involved in the translational and rotational movements experienced by a machine tool during an earthquake. Finally, the 2004 Chūetsu earthquake, with the largest vibration data, was selected for the calculation and evaluation of 
the vibration over the mock-up in order to propose a set of reliable risk assessment criteria for machine tools.

\section{EXISTING SEISMIC DATA IN JAPAN}

Given the large amount of seismic data that exist in Japan, just the data of the following three large earthquakes was analyzed: the 1995 Great Hanshin earthquake [10], the 2004 Chūetsu earthquake [10], and the 2011 Tōhoku earthquake and tsunami [10]. In Fig. 1, the relationship between acceleration and time due to seismic activity at each of the locations is shown. Here, it was possible to observe that each earthquake has its own characteristic vibration time, period and amplitude. Thus, assuming that a certain structure was placed at the place of each of the aforementioned earthquakes, the motion behavior of said structure would be completely different in each case.

Moreover, if several of these structures are placed at a single earthquake area but with different supporting methods or positioned in different directions, the behavior generated would also be different.

Particularly, considering that the largest acceleration measurements in each of the earthquakes is shown in Fig. 1, it can be assumed that in the hypocenter neighborhood and regions dominated by soft ground, as in the 2004 Chūetsu earthquake, larger vibrations occur. Therefore, the maximum acceleration vector data and time values considered for this research will be the presented in Fig. 1 and Table 1.
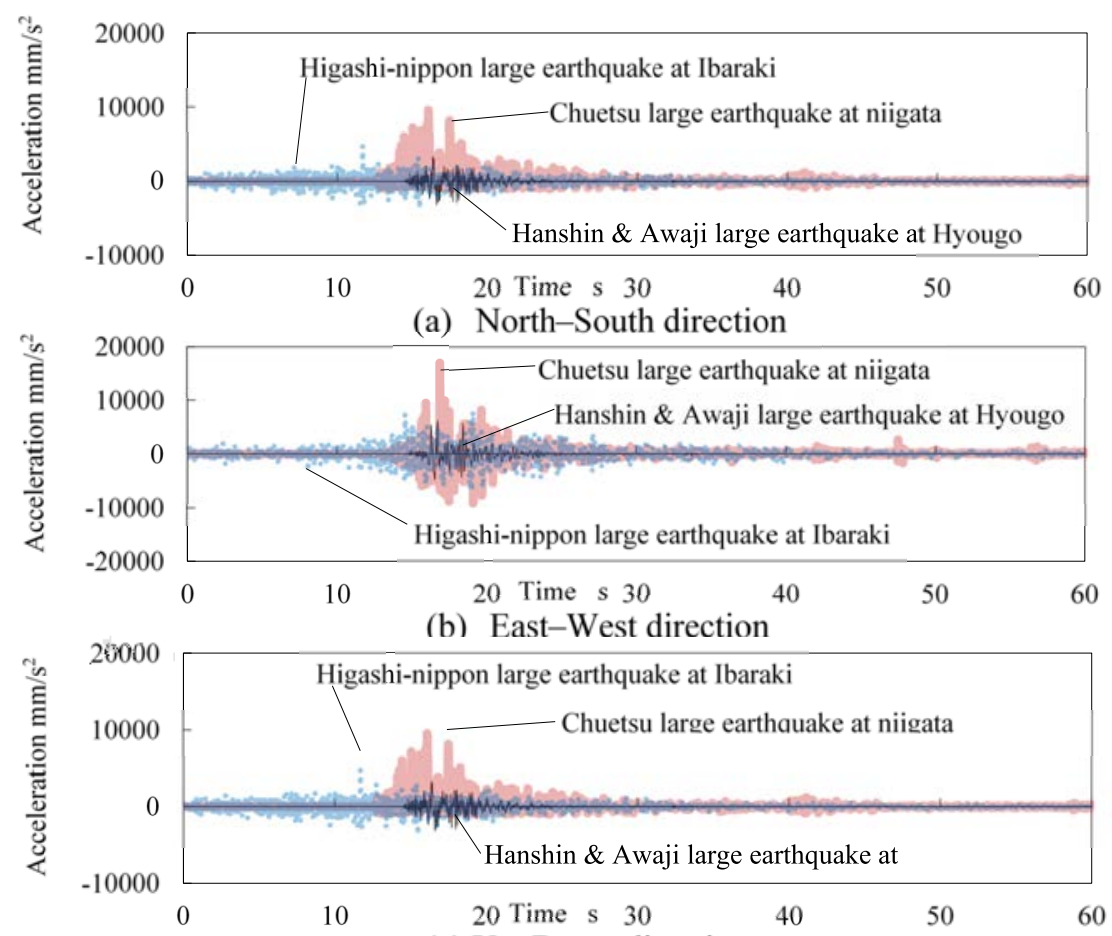

(c) Up-Down direction

Figure 1: Relationship between the acceleration and the time for Hanshin and Awaji large earthquake disaster at 1995, Chūetsu large earthquake disaster at 2004 and Higashi-nippon large earthquake disaster at 2011. 
Table 1: Maximum acceleration vector data and time values during the 1995 Great Hanshin earthquake, the 2004 Chūetsu earthquake, and the 2011 Tōhoku earthquake and tsunami.

\begin{tabular}{|c|c|c|c|c|c|}
\hline Earthquakes & $\begin{array}{c}\text { North- } \\
\text { South }\end{array}$ & East-West & Up-Down & Horizontal plane & Three-dimensional plane \\
\hline $\begin{array}{c}1995 \text { Great } \\
\text { Hanshin }\end{array}$ & $\begin{array}{c}5789.7 \\
{[18.0 \mathrm{~s}]}\end{array}$ & $\begin{array}{c}6172.8 \\
{[16.7 \mathrm{~s}]}\end{array}$ & $\begin{array}{c}3322.4 \\
{[16.4 \mathrm{~s}]}\end{array}$ & $\begin{array}{c}8478.6,[16.8 \mathrm{~s}], \\
\text { Direction: } 142.8^{\circ}\end{array}$ & $\begin{array}{c}8910.1,[16.7 \mathrm{~s}], \\
\text { Angle of declination:18.6 } \\
\text { Direction: } 315.5^{\circ}\end{array}$ \\
\hline 2004 Chūetsu & $\begin{array}{c}9237.0 \\
{[22.5 \mathrm{~s}]}\end{array}$ & $\begin{array}{c}16758.3 \\
{[16.9 \mathrm{~s}]}\end{array}$ & $\begin{array}{c}9550.0 \\
{[16.1 \mathrm{~s}]}\end{array}$ & $\begin{array}{c}16758.4,[16.9 \mathrm{~s}], \\
\text { Direction: } 90.2^{\circ}\end{array}$ & $\begin{array}{c}16818.8,[16.88 \mathrm{~s}], \\
\text { Angle of elevation: } 4.9^{\circ}, \\
\text { Direction: } 359.8^{\circ}\end{array}$ \\
\hline 2011 Tōhoku & $\begin{array}{c}8558.9 \\
{[16.1 \mathrm{~s}]}\end{array}$ & $\begin{array}{c}7920.0 \\
{[19.1 \mathrm{~s}]}\end{array}$ & $\begin{array}{c}4809.1 \\
{[11.7 \mathrm{~s}]}\end{array}$ & $\begin{array}{c}\text { 8807.9, [16.1s], } \\
\text { Direction: } 340.7^{\circ}\end{array}$ & $\begin{array}{c}8819.5,[16.1 \mathrm{~s}], \\
\text { Angle of elevation: } 2.9^{\circ}, \\
\text { Direction: } 103.7^{\circ}\end{array}$ \\
\hline
\end{tabular}

Unit is $\mathrm{mm} / \mathrm{s}^{2}$, [ ] is the time from the start of earthquake to the time at maximum acceleration and direction: North $=90^{\circ}$, South $=270^{\circ}$, East $=0^{\circ}$, West $=180^{\circ}$

In this regard, the maximum acceleration vector of the Chūetsu large earthquake disaster is 2 times more intense than the other earthquakes considered. In perspective, this is the equivalent to 1.5 times the gravitational acceleration and, thus, can be regarded as very violent vibration. Similarly, the time values corresponding to the maximum acceleration vector data were significantly different between each other. Therefore, the motion behavior of structures during an earthquake becomes exceptionally complex to model and, consequently, a significant consideration for the development of a risk assessment criteria for machine tools.

\section{A MODEL FOR THE ASSESSMENT OF MACHINE TOOL MOTION BEHAVIOR}

Research on the motion behavior of machine tools has been focused on internal structural analyses through mathematical models [11] and the influence of vibration on the deterioration of machine tools [12]. Nevertheless, considering that large deformations due to earthquake accelerations out of clearance ranges have not been observed, an approach on the motion behavior of the structure of the machine tool itself has not been proposed yet [8].

Here,previous researches have stressed the importance of attenuating the hazards of earthquakes, in the form of damage caused by overturning, falling, impacting or sliding, to operational equipment in critical facilities [13]. In the same way, renowned institutions have standardized the importance of anchoring to prevent machine tools from moving or rotating due to seismic activity [14]. Accordingly, world emergency government agencies promote the usage of anchoring methods [15].

However, given that the usage of fixed mounts or concrete anchoring on machine tools reduces the flexibility of the production area, screw jacks and leveling jacks are common even in seismic prone areas, and research regarding the role of these mounts in machine tools has been explored in recent years [16]. This research proposes risk assessment criteria that contribute to the selection of proper anchoring. Thus, contributing to prevent machine tools from catastrophically rolling over, tumbling or experiencing motion phenomena due to seismic vibrations. The mock-up structure utilized was designed so that the supports of the structure, and the structure itself, would mimic a machine tool. Moreover, as shown in Fig. 2 , given the many available support configurations, it was considered that a mathematical model for the motion phenomena should not rely on the amount of supports. 
(a)

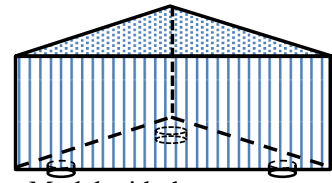

Model with three supports

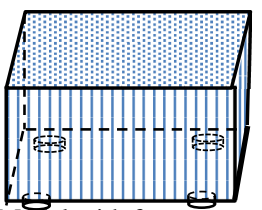

(b) Model with four supports

Figure 2: Some machine tool support configurations that can be considered.

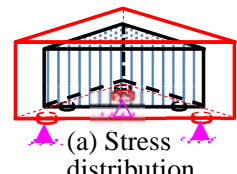

distribution

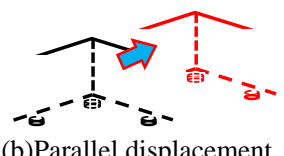

(b)Parallel displacement

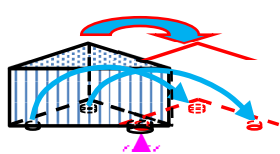

(c) Rotational movement

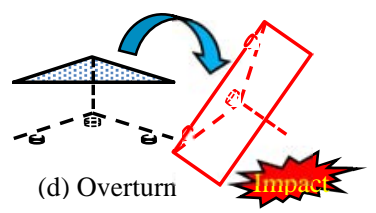

Figure 3: Considered possible machine tool movement scenarios.

The machine tool behavior during an earthquake was constrained to four main motion scenarios. These scenarios were defined as shown in Fig. 3. Namely, Fig. 3(a) refers to the stress distribution or the deformation experienced by the structure in a fixed-support scenario.

This scenario, in which vibrations affect the structural internal integrity of the machine tool, has been widely explored in previous researches and would be uncommon in earthquake prone areas and, thus, was not explored in detail [10], [11]. Moreover, Fig. 3(b) refers to a parallel displacement scenario and Fig. 3(b) refers to a rotational movement scenario. Finally, Fig. 3(d) assumes a catastrophic overturn scenario experienced by the tool machine. Specifically, Fig. 3(b) and (c) were considered to as relevant elements on a risk assessment criteria given that they could be used to analyze possible collisions between the machine tool and its surroundings; and Fig. 3(d) was used to evaluate the scenario in which the machine tool experiences a catastrophic overturn or tumbling.

(1) Mathematical model for the parallel displacement scenario (Fig. 3(b)): In this scenario, it was considered that when a force $F(=M \alpha(t))$ acting over the structure center of gravity, resultant from the acceleration generated by an earthquake $\alpha(t)$, became larger than the friction force $\pm \mu M g$ ( $\mu$ = Coefficient of friction, $M=$ mass of a structure, $g=$ Gravity acceleration) a parallel movement of the structure would occur in the form of stick slipping. This mathematical model is represented in Fig. 4, in which an earthquake exhibits a north-south oscillation with a $\alpha(t)$ acceleration. Here, the south and north directions were defined as the negative and the positive coordinates, respectively. The mathematical model analyzed the parallel movement scenario during a single oscillation cycle, while at the end of the cycle the condition of the structure was defined to be static.

The acceleration curve for a single oscillation cycle was approximated using several rectangular partitions of the acceleration at every $\Delta t$ time step $\left(=\Delta t \times \alpha_{n}\right)$. Here, it is possible to observe that the impulse $\left(M\left(\alpha_{\mathrm{n}}-\mu \mathrm{g}\right) \Delta t\right)$ converges to the momentum over the structure $\left(M V_{\mathrm{n}}\right)$. Where, $V_{\mathrm{n}}$ is the required speed for the structure to observe stick slipping. Considering the kinetic energy acting over the structure $\left(=1 / 2 M V_{\mathrm{n}}^{2}\right)$ is the work required for the structure to move a distance $\mathrm{x}(\mu \mathrm{Mg} \mathrm{x})$, the parallel displacement can be calculated by adding up the total amount of partitions as shown in eqn (1). 


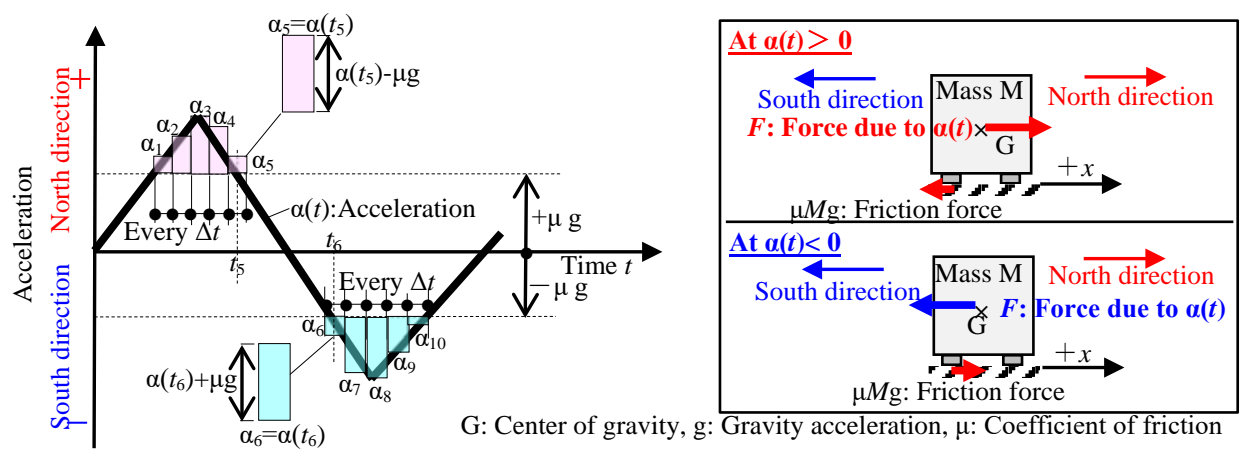

Figure 4: Simple model used for the parallel displacement scenario calculations.

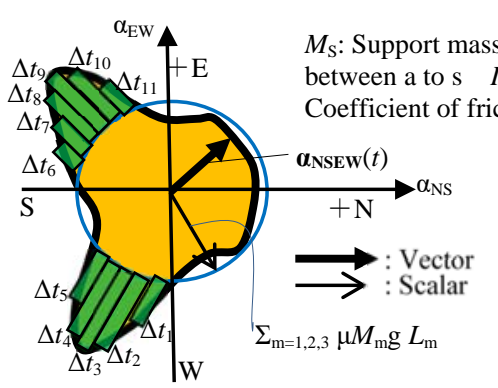

(a) Earthquake acceleration vector in the horizontal plane
$M_{\mathrm{S}}$ : Support mass No.S, $I_{\mathrm{G}}$ : Inertia moment for the center of gravity, $L_{\mathrm{as}}$ : distance between a to s $I_{\mathrm{a}}$ : Inertia moment for point a, g: Gravity acceleration $\mu$ : oefficient of friction G: Center of gravity, ०: Support points

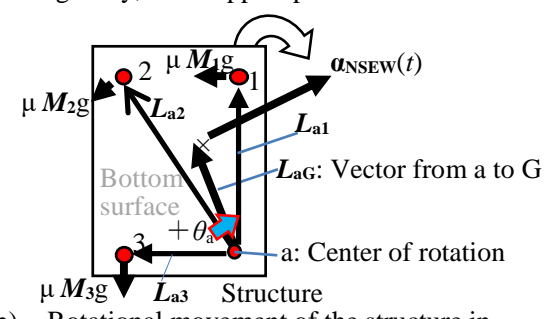

(b) Rotational movement of the structure in the horizontal plane

Figure 5: Simple model used for the rotational movement scenario calculations.

This eqn considered the partitions shown in Fig. 5 to calculate the parallel displacement in the north direction $X_{\mathrm{n}}$ for a single oscillation cycle with positive acceleration ( $\mathrm{n}=$ the amount of partitions). Likewise, the parallel displacement in the south direction $X_{\mathrm{s}}$

$$
X_{\mathrm{n}}=\sum_{\mathrm{n}=1 \sim 5} \frac{1}{2 \mu \mathrm{g}}\left(\alpha_{\mathrm{n}}-\mu \mathrm{g}\right)^{2} \Delta t^{2}-\sum_{\mathrm{n}=6 \sim 10} \frac{1}{2 \mu \mathrm{g}}\left(\alpha_{\mathrm{n}}+\mu \mathrm{g}\right)^{2} \Delta t^{2}
$$

can be calculated through eqn (1). Thus, the total parallel movement $X_{\mathrm{ns}}$ in the south and north directions can be calculated as " $X_{\mathrm{n}}+X_{\mathrm{s}}$ ”. In the same way, other parallel displacement combinations such as the east and west directions $X_{\text {ew }}$ are also possible.

However, this model does not consider a change in the ground shape nor in the ground friction coefficient due to an earthquake oscillation in the up-down direction. Nevertheless, it was possible to present a parallel displacement assessment approach dependent on earthquake acceleration and ground friction coefficient and, allowing the use of a small mock-up structure, not on the structure mass.

(2) Mathematical model for the rotational movement scenario (Fig. 3(c)): This scenario considered a north-south and east-west composite acceleration vector defined as 
$\boldsymbol{\alpha}_{\text {NEWs }}(t)$ acting over the structure center of gravity and generating a resultant force $\boldsymbol{F}$ (= $\left.\operatorname{M\alpha } \boldsymbol{\alpha}_{\text {NEw }}(t)\right)$. Moreover, as shown in Fig. 5, in this scenario the clockwise direction from the center of rotation was defined as the $+\theta_{\mathrm{a}}$ rotational coordinate; and the center of rotation was defined to be a single support, in this case support $a$. Here, each support of the structure exhibits a friction force $\mu M_{\mathrm{s}} \mathrm{g}\left(\mu\right.$ : coefficient of friction, $M_{\mathrm{s}}$ : mass on support $s, g$ : gravity acceleration, where s=1, 2, $3 \ldots$...). Considering a $\mathbf{L}_{\mathbf{a G}}$ vector from the center of rotation to the center of gravity of the structure and a vector $\boldsymbol{L}_{\text {as }}$ from support $a$ to support $s$, it was thought that a rotational movement would occur when the cross product " $M \boldsymbol{\alpha}_{\text {NSEW }}(t) \times \mathbf{L}_{\mathbf{a G}}$ " was larger than the sum " $\sum_{\mathrm{s}=1,2, \ldots} \ldots$ (number of the supports-1) $\mu M_{\mathrm{s}} \mathrm{g} L_{\mathrm{as}}$ ".

In Fig. 5(a) it is possible to observe a depiction of the acceleration vector and the sum " $\sum_{\mathrm{s}=1,2, \text { (number of the supports }-1)} \mu M_{\mathrm{s}} \mathrm{g} L_{\mathrm{as}}$ " is represented as a scalar. The blue circle represents the rotational movement threshold and the rectangular green areas represent the time intervals that experienced a rotational movement, movement magnitude, and the direction in which the movement happened during an earthquake. Here, it is possible to observe that the impulse at each $\Delta t_{\mathrm{i}}$ interval of time is " $\left[\left(\operatorname{M\alpha } \boldsymbol{\alpha}_{\mathrm{NSEW}}(t) \times \mathbf{L}_{\mathbf{a G}}\right)-\sum_{\mathrm{s}=1,2,} \ldots\right.$ (number of the supports -1$\left.) \mu M_{\mathrm{s}} \mathrm{g} L_{\mathrm{as}}\right] \Delta t$ " converges to the angular momentum on the structure $I_{\mathrm{a}} \omega_{\mathrm{a}}(t)\left(I_{\mathrm{a}}\right.$ : moment of inertia over the support point a of the structure, $\omega_{\mathrm{a}}(t)$ : angular velocity over the support point $a$ of the structure at time $t$ ).

Considering the angular kinetic energy acting over the structure $\left(=1 / 2 I_{\mathrm{a}} \omega_{\mathrm{a}}(t)^{2}\right)$ is the work required for the structure to rotate a $\theta_{\mathrm{x}}$ angle $\left(\mu M g|\mathbf{L a G}| \theta_{\mathrm{x}}\right)$ over the support point $a$, the rotational movement can be calculated by adding up the total amount of partitions as shown in eqn (2)

$$
\theta_{\mathrm{x}}=\sum_{\mathrm{n}=1 \sim 11} \frac{1}{2 \mu \mathrm{g} M I_{\mathrm{a}}}\left[\left(M \boldsymbol{\alpha}_{\mathrm{NSEW}}(t) \times \boldsymbol{L}_{\mathrm{aG}}\right)+\sum \mathrm{S}_{=1,2,} \cdot(\text { number of the supports }-1) \mu \boldsymbol{M}_{\mathrm{s}} \mathrm{g} \times \boldsymbol{L}_{\mathrm{as}}\right]^{2} \Delta t_{\mathrm{n}}{ }^{2}
$$

It must be considered that this model does not consider a change in the ground shape nor in the ground friction coefficient due to an up-down oscillation. Moreover, the total earthquake oscillation time was divided in time $\Delta t$ partitions and the rotational movement of the structure at each $\Delta t$ could be estimated through eqn (2). Here, a coherent approach to estimate the rotational movement of the structure was presented.

(3) Mathematical model for the overturn scenario (Fig. 3(d)): The mathematical model for the structure overturn scenario is shown in Fig. 6. Specifically, this scenario models the event in which the oscillation generated movement is opposed by large friction forces, large friction coefficients or a ground protuberance on a specific support and overturning occurs. Here, the composite vector $\boldsymbol{\alpha}_{\mathrm{NEwS}}(t)$, which represents the acceleration in north-south and east-west directions, and the resultant force $\boldsymbol{F}\left(=\operatorname{M\alpha } \boldsymbol{\alpha}_{\mathrm{NEWs}}(t)\right)$ act over the center of the gravity of the structure. It is possible to observe that, at the time of an earthquake, the acceleration composite vector in the up-down directions can be defined as " $\mathbf{g}-\boldsymbol{\alpha}_{\mathbf{u d}}(t)$ " $(\boldsymbol{\alpha} \mathbf{u d}(t)$ : earthquake acceleration at time $t$ in the up-down direction, g: gravity acceleration). If the vector from the support point $a$ to the center of gravity is considered as " $\mathbf{L a G s " , ~ t h e ~ m o m e n t ~ i n ~ t h e ~ c l o c k w i s e ~}$ direction over the support point $a$ can represented as "Monsew $(t) \times \boldsymbol{L}_{\mathbf{a G}}$ ". Here, it can be observed that the gravity acceleration opposes the overturning motion and the moment can be defined as $\mathbf{M}\left(\mathbf{g}-\boldsymbol{\alpha}_{\mathbf{u d}}(t)\right) \times \mathbf{L}$ aG. Thus, a criterion in which no overturn occur is described on eqn (3)

$$
\text { No overturn } \Rightarrow\left(\mathbf{g}-\boldsymbol{\alpha}_{\mathbf{u d}}(t)\right) \times \boldsymbol{L}_{\mathbf{a G}}>\boldsymbol{\alpha}_{\mathrm{NSEW}}(t) \times \boldsymbol{L}_{\mathrm{Ag}} \text {. }
$$




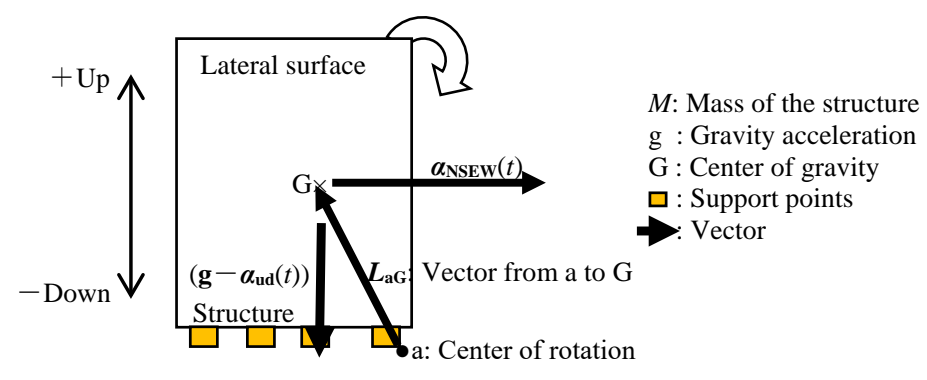

Figure 6: Simple model used for the overturn scenario calculations.

In this regard, it is possible to appreciate that if the earthquake acceleration in the up-down direction reduces the influence of the gravity acceleration, the structure would likely overturn. It also can be observed that if large accelerations in the up-down direction are experienced, even if there are just mild horizontal earthquake accelerations, the chances of overturning are high. Moreover, if the center of gravity increases in height the chances of overturn increase because the right segment of eqn (3) increases in value. Here, a coherent approach, which partitions the earthquake oscillation time $\Delta t$ intervals, to estimate the overtun movement of the structure was presented. Finally, the only support point considered was point $a$; however, the other support points can also be considered through the same method.

\section{EXPERIMENTAL EVALUATION OF THE DEVELOPED MOTION MODELS}

The motion behavior models developed in the previous section are evaluated through the following experimental set-up. Particularly, the developed machine tool mock-up structure consisted of several bolts, nuts and plates. The parameters of the structure are shown in Fig. 7, and the specifications of the lathe linear motor table are shown in Table 2 and Fig. 8, respectively. Here, the table can move at $2 \mathrm{~g}$ (g: acceleration of gravity) in the $\mathrm{X}$ direction which is coherent with earthquake accelerations. Moreover, a $412 \mathrm{~mm} \times 427 \mathrm{~mm} \times 9 \mathrm{~mm}$ steel plate was fixed over the table, and the mock-up structure was positioned as shown in Fig. 8. Additionally, the supports number, mass and height of the center of gravity can be modified.

As mentioned before, screw jacks, leveling pads and leveling jacks are used for the support of machine tools. The mock-up structure simulates this anchoring regime through supports that mimic screw jacks and different foundation conditions that mimic leveling pads or oil present in the production area floor. The selected foundation, a metal-metal interface, was meant to analyze the harshest foundation conditions during an earthquake that could lead to movement of the structure. Here, it must be noted that a metal-concrete interface exhibited a $1 / 10$ of the support stiffness of a metal-metal interface in previous researches [16]. On the other hand, the friction coefficient of the different foundation conditions, shown in Fig. 9, and the plate acceleration in the $\mathrm{X}$ direction, shown in Fig. 10, were measured before to be used in the experimentation regarding the motion models. The structure gravity center over the plate was pulled at $300 \mathrm{~mm} / \mathrm{s}$ using a very fine wire; the pulling load was then measured with a pull tension gauge and the dynamic friction coefficient was calculated using the pulling load. The accelerations were calculated using the relationship between time and table position data obtained through high speed camera measurements.

(1) Evaluation of the mathematical model of the parallel displacement scenario: Evaluation of mathematical model (eqn (1)) for parallel movement of a structure was performed using the experimental conditions shown in Table 3. Particularly, masses of the 


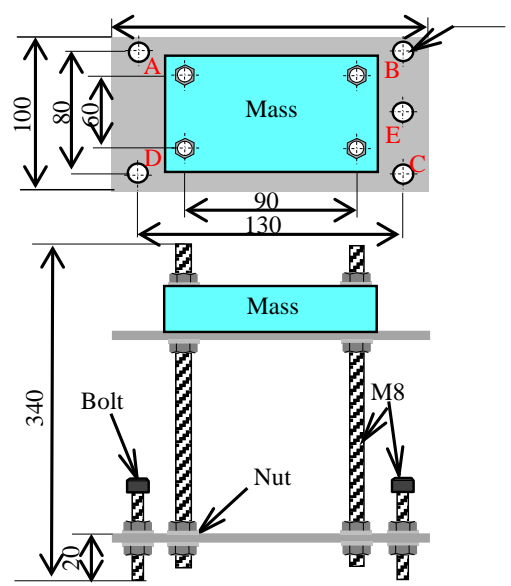

(a) Drawing of the structure

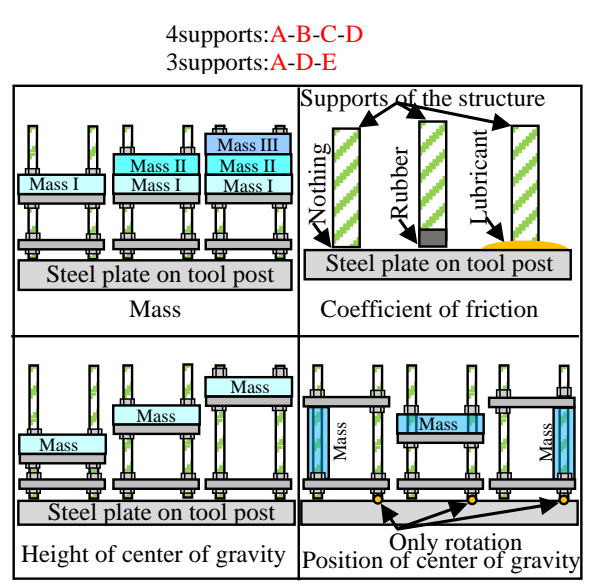

(b) Available parameters

Figure 7: Schematics of the machine tool mock-up structure.

Table 2: Specifications of the used linear motor lathe.

\begin{tabular}{|c|c|c|}
\hline \multirow{6}{*}{ 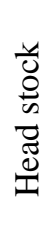 } & Max. spindle speed & $10000 \mathrm{~min}-1$ \\
\hline & \begin{tabular}{|l|} 
Stroke on $\mathrm{Z}$ direction \\
\end{tabular} & $200 \mathrm{~mm}$ \\
\hline & Max. acceleration on Z direction & $12.1(1.23 \mathrm{G}) \mathrm{m} / \mathrm{s} 2$ \\
\hline & Max. speed on Z direction & $90 \mathrm{~m} / \mathrm{min}$ \\
\hline & Max. load on Z direction & $1674 \mathrm{~N}$ \\
\hline & Positioning accuracy of $\mathrm{Z}$ & $0.3 \mu \mathrm{m}$ \\
\hline \multirow{6}{*}{. } & Stroke on $\mathrm{X}$ direction & $195 \mathrm{~mm}$ \\
\hline & Max. acceleration on $\mathrm{X}$ direction & $19.6(2.0 \mathrm{G}) \mathrm{m} / \mathrm{s} 2$ \\
\hline & Max. speed on X direction & $110 \mathrm{~m} / \mathrm{min}$ \\
\hline & Max. load on X direction & $1674 \mathrm{~N}$ \\
\hline & Positioning accuracy of $\mathrm{X}$ & $0.5 \mu \mathrm{m}$ \\
\hline & Table size & $410 \times 80 \times 434 \mathrm{~mm}$ \\
\hline
\end{tabular}

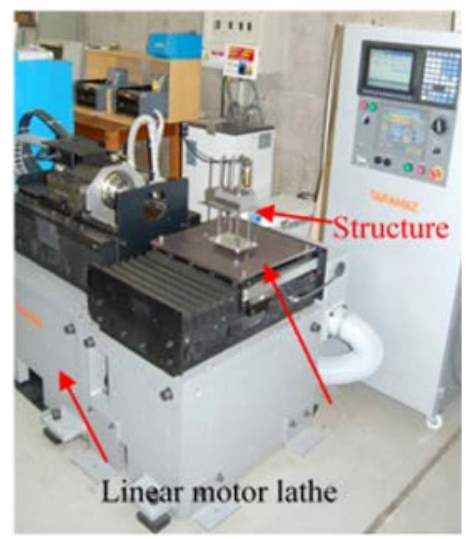

Figure 8: Mock-earthquake experimental setup. 


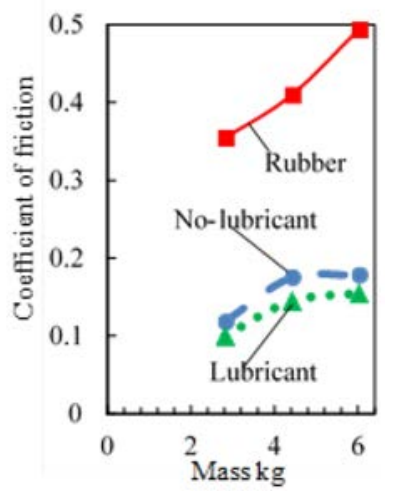

Figure 9: Coefficient of friction between the structure and the plate on the tool post.

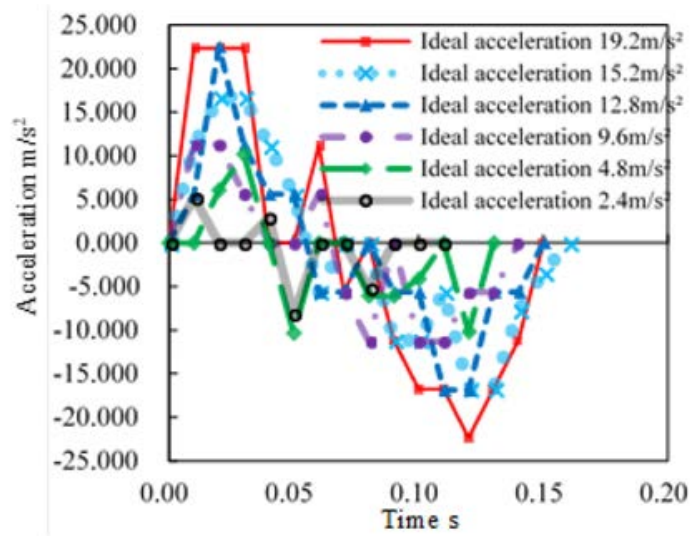

Figure 10: Acceleration curve of the tool post.

Table 3: Experimental conditions for the evaluation of the parallel displacement scenario.

\begin{tabular}{|l|l|}
\hline Items & Conditions \\
\hline Acceleration $\mathrm{m} / \mathrm{s}^{2}$ & $2.4,4.8,9.6,12.8,19.2$ \\
\hline Acceleration curve & $\rightarrow$ See Fig.10 \\
\hline $\begin{array}{l}\text { Available interfaces between the } \\
\text { structure and the plate }\end{array}$ & None \\
\cline { 2 - 2 } & ISO VG5 \\
\cline { 2 - 2 } Mass m kg & $\begin{array}{l}\text { Rubber } \\
\text { 2.8,4.4,6.0 } \\
\text { Position See Fig. 9 }\end{array}$ \\
\hline
\end{tabular}


structure were 2.8, 4.4 and $6.0 \mathrm{~kg}$; this was deemed as important considering there is a nonlinear relationship between the coefficient of friction and mass of the structure. Additionally, the friction conditions between the structure and the plate were no-lubricant, lubricant oil with ISO VG5 and rubber seat regimes. Finally, after the plate was displaced one cycle of acceleration and deceleration as shown in Fig. 10 and Table 3, the parallel displacement of the structure was measured with a tape measure. The results regarding evaluation of the mathematical model for the parallel movement of the structure are shown in Fig. 11. Here, it was thought that the mathematical model for the parallel displacement was valid for the calculation of the parallel displacement during an earthquake because of the coherence between the experimental results and the calculations. Similar as exposed in the mathematical model (1), the experimental results show that the relationship between the mass of the structure and the parallel movement could be negligible. This, considering that when the mass of the structure was changed, the coefficient of friction also changed. Here, it was concluded that the parallel movement exhibited a non-linear behavior and that the model could be applied to machine tools of multiple dimensions.

Moreover, as shown in Fig. 11 the displacement exhibited by was remarkably similar between the lubricant and no-lubricant cases. Thus, it was considered lubricant in the production area would not play a significant role in this motion scenario. However, when a rubber pad was used, the structure over turned in every case, and the parallel movement was not measured which could be considered in the support selection process after a risk assessment. Conclusively, the parallel movement will be influenced by the coefficient of

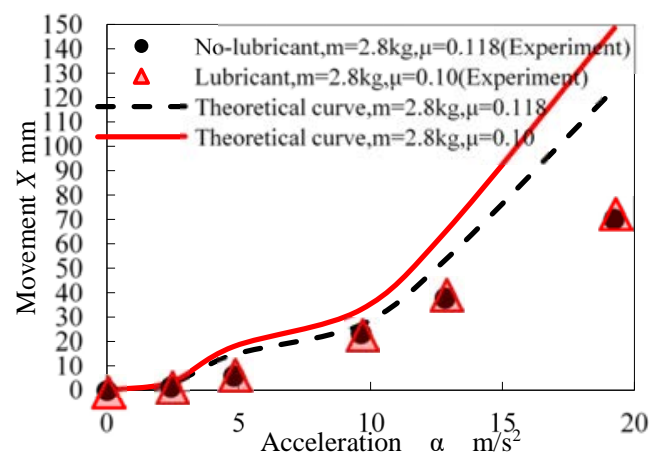

(a) Mass $m=2.8 \mathrm{~kg}$

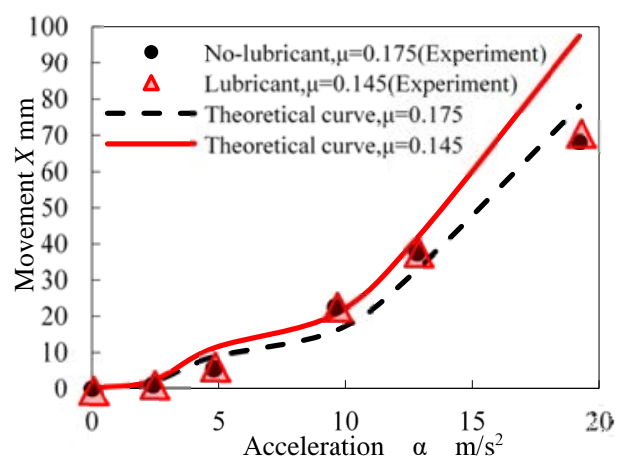

(b) Mass $m=4.4 \mathrm{~kg}$

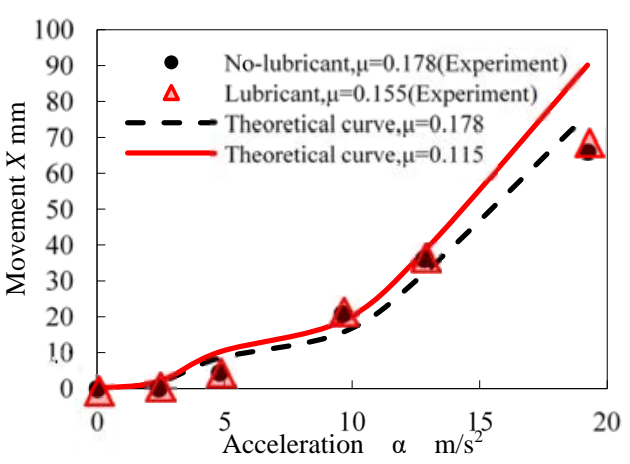

(c) Mass $m=6.0 \mathrm{~kg}$

Figure 11: Evaluation results of the parallel movement scenario. 
friction and the acceleration of the earthquake; if the coefficient of friction becomes large, the parallel displacement becomes small and the chances of overturning increase. On the other hand, it was observed that when the mass of the structure was small ( $2.8 \mathrm{~kg})$ the contact between the structure and the ground was unstable. Here, the displacement value difference between the experiment and the theoretical value became significantly large.

(2) Evaluation of the mathematical model of the rotational movement scenario:

Evaluation of the mathematical model (eqn (2)) for the rotational movement of a structure was performed using the experimental conditions shown in Table 4. Namely, the mass of the structure was $4.4 \mathrm{~kg}$, the distances from the rotational center to the center of the structure on the plate were 30, 75 and $120 \mathrm{~mm}$, and contact conditions between the structure and the plate were no-lubricant and lubricant oil with ISO VG5 regimes.

Finally, after the plate was moved with one cycle of acceleration and deceleration such as Fig. 10 and Table 4, the rotational movement of the structure was measured using a protractor. The results regarding the evaluation of the mathematical model for the structure rotational movement are shown in Fig. 12. From this, it was thought that the mathematical model for the rotational movement was adequate to some extend because of the coherence between the results and the experimentation. In this matter, the following factors were considered to influence the rotational movement of the machine tool: the contact coefficient of friction, the reaction forces of each support, the position of the center of gravity and the earthquake acceleration. Consequently, by using the mathematical model (eqn (2)) an anchoring method to avoid rotational movement due to seismic activity could be selected. From the results, it was observed that as the support distance from the center of gravity become larger, the rotational movement of the structure increases and, as the structure becomes unstable, overturning occurs. Thus, factories and workshops in areas that are prone to mild seismic activity could arrange its machine tools with countermeasures, using these models, against parallel and rotational movements to avoid catastrophic overturns.

(3) Evaluation of the mathematical model of the overturn scenario:

Evaluation of mathematical model (eqn (3) for the structure overturn scenario was performed using the experimental conditions shown in Table 5. Namely, the mass of the structure was $4.4 \mathrm{~kg}$, the contact conditions between the structure and the plate were no-lubricant, lubricant oil with ISO VG5 and rubber seat regimes. However, it should be noted that when only rubber pad was used, the structure overturned. Also, experimentation consisted in using the Models

Table 4: Experimental conditions for the evaluation of the rotational movement scenario.

\begin{tabular}{|l|l|}
\hline Items & Conditions \\
\hline Acceleration m/s & $2.4,4.8,9.6,12.8,19.2$ \\
\hline Acceleration curve & $\rightarrow$ See Fig. 10 \\
\hline $\begin{array}{l}\text { Available interfaces between the } \\
\text { structure and the plate }\end{array}$ & None \\
\cline { 2 - 2 } & ISO VG5 \\
\hline Mass m kg & 4.4 \\
\hline $\begin{array}{l}\text { Distance from center of gravity D } \\
\text { mm }\end{array}$ & \begin{tabular}{l}
$30,75,120$ \\
\hline Position
\end{tabular} \\
\hline
\end{tabular}




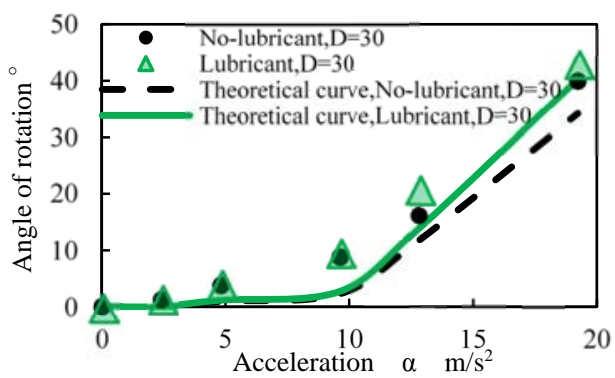

(a) Distance from center of gravity $D=30 \mathrm{~mm}$.

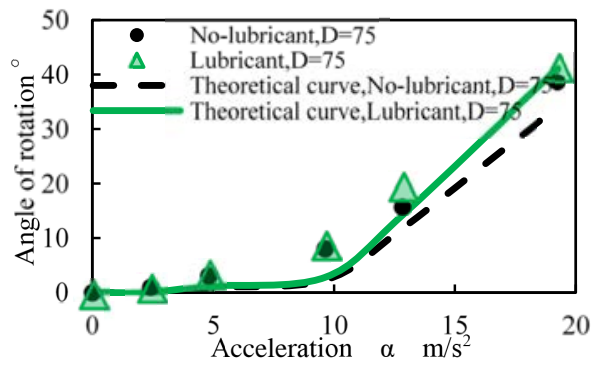

(b) Distance from center of gravity $D=$ $75 \mathrm{~mm}$.

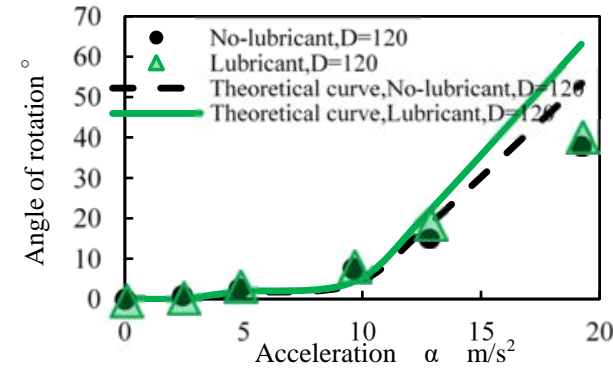

(c) Distance from center of gravity $D=$ $120 \mathrm{~mm}$.

Figure 12: Evaluation results for the rotational movement scenario.

Table 5: Experimental conditions for the evaluation of the overturn scenario.

\begin{tabular}{|c|c|c|}
\hline Items & Conditions & \multirow{3}{*}{ Position } \\
\hline Acceleration $\mathrm{m} / \mathrm{s}^{2}$ & $2.4,4.8,9.6,12.8,15.2,19.2$ & \\
\hline Acceleration curve & $\rightarrow$ See Fig. 10 & \\
\hline \multirow{3}{*}{$\begin{array}{l}\text { Available interfaces } \\
\text { between the structure } \\
\text { and the plate }\end{array}$} & None & \multirow{4}{*}{ 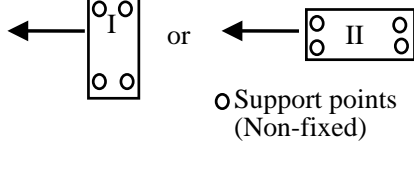 } \\
\hline & ISO VG5 & \\
\hline & Rubber & \\
\hline Mass $m$ kg & 4.4 & \\
\hline
\end{tabular}

I and II (Table 5) and moving the plate one cycle of acceleration and deceleration, as in Fig. 10 and Table 5, to analyze the overturn behavior. The results regarding the evaluation of mathematical model for the structure overturn scenario are shown in Fig. 13. From this, it was thought that the mathematical model for overturn scenario can be used for the calculation of the overturn scenario because of the coherence between the experimental results and the calculations. Additionally, the structure overturn scenario was deemed to be influenced by the moment of the earthquake acceleration and gravity restoring force. Consequently, it can be argued that the machine tool overturn scenario can be investigated by using the data of past earthquakes as defined in section 2 and the mathematical model for the overturn scenario (eqn (3)). 


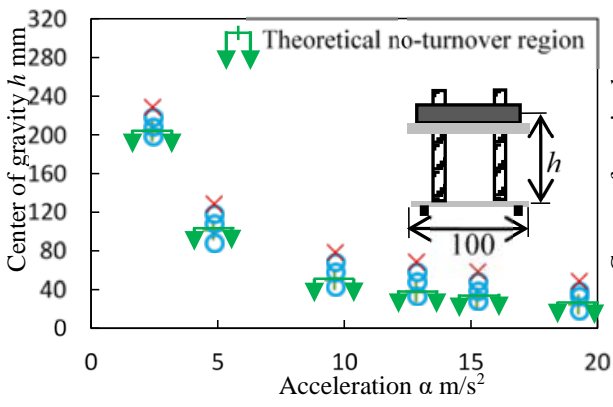

(a) Model I.

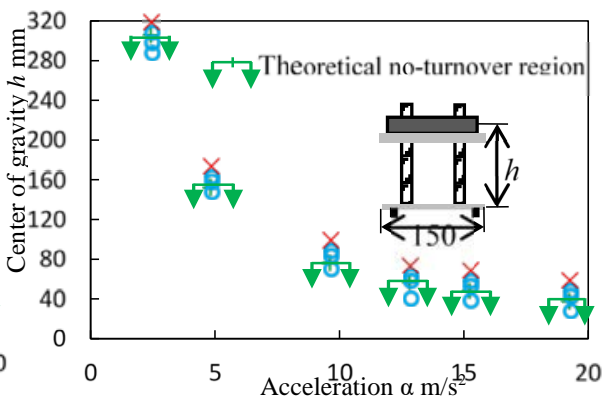

(b) Model II.

Figure 13: Evaluation results of the overturn scenario.

However, the gravitation restoring force over the structure is influenced by the earthquake acceleration in the up-down directions, while the restoring force is also influenced of the mass and height of the structure. In the risk assessment stage, these considerations should be performed for a safe earthquake-resilient anchoring selection. Finally, it should be considered that the selection of an overturn-resilient machine anchoring takes into account the height of the center of gravity and the relationship between position, the support points and the center of gravity as done by the proposed mathematical model.

\section{CONSIDERATIONS REGARDING THE MACHINE TOOL MOTION BEHAVIOUR DURING A REAL EARTHQUAKE}

Data of an internal survey of the machining workshop of the Nagaoka University of Technology in the aftermath of the 2004 Chuetsu large earthquake [2], [9] showed that among a total of 84 machine tool devices, 1 experienced catastrophic overturn, 2 experienced large displacements that ended in catastrophic impacts between machine tools and 81 experienced displacements. Moreover, among the machines that experienced displacements none of them presented accuracy changes out of the determined clearance ranges as mentioned in previous research regarding the effects of earthquake accelerations over machine tool components [8]. Specifically, data regarding a CNC machining center recorded on October 23rd at the machining workshop of the Nagaoka University of Technology, in the aftermath of the 2004 Chuetsu large earthquake, is shown in Table 6. Here, the actual displacements due to the earthquake acceleration where measured with respect to the workshop standard floor markings for the CNC machining center that indicated its original position. In the same way, the parallel and rotational movements of the CNC machining center using the aforementioned mathematical models (eqns (1) and (2)) are also shown. The floor area occupied by the machining center was $2166 \mathrm{~mm} \times 2685 \mathrm{~mm}$, and its mass $M$ was $6500 \mathrm{~kg}$.

During the calculations, the structure of the machine tool was assumed to be a rectangular block with uniformly distributed density and height $h$, and supported on its four base corners. The distance from the support point of the rotational center to the center of gravity on the structure was $L$, the moment of inertia $I_{\mathrm{a}}$ in the eqn (2) was calculated as " $I_{\mathrm{a}}=M\left(a^{2}+b^{2}\right) / 12$ $+M L^{2}$ ". Here, the calculations were performed considering the acceleration curves in Fig. 1. The results of eqns (1) and (2) are shown in Table 6. The foundation friction coefficient $\mu$ at the time of the calculation at the machine workshop of the Nagaoka University of Technology was 0.132 . 
Table 6: Comparison between real parallel and rotational movement of a CNC machining center under an earthquake and the calculated parallel and rotational movements using the proposed method.

\begin{tabular}{|l|c|c|c|}
\hline \multirow{2}{*}{ Machine tool } & \multicolumn{2}{|c|}{$\begin{array}{c}\text { Parallel movement relative } \\
\text { to gravity center }\end{array}$} & $\begin{array}{c}\text { Rotational } \\
\text { movement } \\
(+: \\
\text { Clockwise) }\end{array}$ \\
\cline { 2 - 4 } & NS direction & EW direction & Real behavior after the 2004 Chuetsu \\
earthquake & S $83.2 \mathrm{~mm}$ & E $132.8 \mathrm{~mm}$ & $+5^{\circ}$ \\
\hline Calculation using eqn (1) and eqn (2) & S $47.3 \mathrm{~mm}$ & E $66.4 \mathrm{~mm}$ & $+2.9^{\circ}$ \\
\hline Calculation accuracy & $56.9 \%$ & $50.0 \%$ & $5.0 \%$ \\
\hline
\end{tabular}

Calculation accuracy [\%] = difference between calculated and real values $\div$ real values $\times 100$.

As a conclusion, the values of the calculated behavior range from $50 \%$ to $60 \%$ of the real behavior at the 2004 Chuetsu large earthquake. Nevertheless, the distance from the Nagaoka University of Technology to the area of the earthquake was $15 \mathrm{~km}$, bringing up different seismic and ground considerations that might explain the observed difference.

However, the mathematical models proposed can calculate with a $50 \%-60 \%$ accuracy the defined phenomena; thus, the models for the parallel and rotational movements were deemed as effective for the machine tool motion behavior calculation during an earthquake.

\section{CONCLUSION}

The results of this study are summarized as follows:

1. Mathematical models for the parallel, rotational and overturn motion phenomena during an earthquake were developed and applied. Here, given that an accuracy of up to approximately $60 \%$ was observed, these models are considered useful for the investigation and development of seismic risk assessment criteria for machine tools.

2. The data from the the 1995 Great Hanshin earthquake, the 2004 Chūetsu earthquake and the 2011 Tōhoku earthquake and tsunami possessed a very different range of accelerations and a variation in the direction of these accelerations. Moreover, the overturn phenomenon was observed to vary widely just by changing the position orientation of the machine tool. Thus, by applying existing seismic data, the overturn or the tumbling phenomena of the machine tool was deemed to be largely influenced by the position and direction of the machine tool which could contribute to the development seismic risk countermeasures.

3. An approach for risk assessment of machine tools subjected to large earthquakes was presented. Here, the approach relied on the estimation of machine tool motion behavior for a risk assessment that provides a better anti-seismic anchoring method selection.

\section{REFERENCES}

[1] Morita, T., Ten years past after the Great Hanshin-Awaji earthquake. Modern Firefighting Co. Ltd., pp. 7-255, 2005. (In Japanese.)

[2] Nagaoka city, The Chüetsu Earthquake (Effect Regarding Risk Management of SelfGoverning Bodies), Gyousei Co. Ltd., pp. 1-224, 2005. (In Japanese.)

[3] Satake, K. \& Hori, M., Sciences of Tōhoku Earthquake, University of Tokyo Press, pp. 1-243, 2011. (In Japanese.) 
[4] Kourakata, I., Report of the damage and the repair condition on the manufacturing industry at the Chūetsu-oki earthquake in Kashiwazaki. Annual Report of Research Institute Hazards \& Disaster Recovery, 2, pp. 109-113, 2008. (In Japanese.)

[5] Moriwaki, T., Risk management of the manufacturing industry at the Great HanshinAwaji earthquake. Trend-eye '95, Kobe City Industrial Foundation, pp. 1-10, 1995. (In Japanese.)

[6] Minami, T., Economy Effects of the Tōhoku Earthquake in Japan, Norinchukin Research Institute Co. Ltd., Financial Market, 2011/04, pp. 1-3, 2011.

[7] Brunsdon, D., Critical Infrastructure and Earthquakes: Understanding the Essential Elements of Disaster Management, Australian Earthquake Engineering Society, 28, pp. 1-7, 2002.

[8] Japan Society of Mechanical Engineers, Report of Great Hanshin-Awaji earthquake (For Mechanical Engineering), Japan Society of Mechanical Engineers, pp. 339-408, 1998. (In Japanese.)

[9] Japan Society of Mechanical Engineers, Report of Tōhoku earthquake (For Mechanical Engineering), Japan Society of Mechanical Engineers, pp. 403-432, 2013. (In Japanese.)

[10] Japan Meteorological Agency, Observed data of major earthquakes, 2017. (In Japanese.) http://www.data.jma.go.jp/svd/eqev/data/kyoshin/jishin/index.html?sess= 6e1b37b3613bd087e7ce042e42f4670b.

[11] Koenigsberger, F., Machine Tool Structures, Pergamon Press Ltd., pp. 451-456, 1970.

[12] Goyal, D., Condition based maintenance of machine tools-A review. CIRP Journal of Manufacturing Science and Technology, 10, pp. 24-35, Aug. 2015.

[13] Friedman, L. \& Porter, K., Use of logic tree analysis for earthquake emergency planning in critical facilities. Proceedings of the Second Conference on Earthquake Hazards in the Eastern San Francisco Bay Area, Division of Mines and Geology Special Publication, eds G. Borchardt et al., California Department of Conservation, 113, pp. 469-473, 1992.

[14] SLAC National Accelerator Laboratory, Machine Tool Requirements, SLAC National Accelerator Laboratory, pp. 1-7, 2013.

[15] Federal Emergency Management Agency, Installing Seismic Restraints for Mechanical Equipment, Federal Emergency Management Agency, pp. 1-147, 2002.

[16] Kono, D. \& Inagaki, T., Stiffness model of machine tool supports using contact stiffness. Precision Engineering, 37(3), pp. 650-657, Jul. 2013. 